Check for updates

Cite this: RSC Adv., 2018, 8, 18381

\title{
Preparation of an octahedral PtNi/CNT catalyst and its application in high durability PEMFC cathodes $\uparrow$
}

\begin{abstract}
Jue Wang, Bing Li, D * Daijun Yang, Hong Lv D and Cunman Zhang*
In order to promote the application of proton exchange membrane fuel cells (PEMFCs) in electric vehicles (EVs), it is important to improve the activity of cathode catalysts and the corrosion resistance of carbon supports under high potentials formed during transient vehicle operating conditions. An octahedral PtNi/ CNT catalyst with a well-defined structure and enhanced oxygen reduction reaction (ORR) performance was prepared through a surfactant-assisted solvothermal method. Its mass activity and specific activity reach 5.5 and 8.5 times those of the commercial Pt/C catalyst, respectively, and its stability is also higher after durability testing. In addition, the membrane electrode assembly (MEA) fabricated using the octahedral PtNi/CNT catalyst in a cathode exhibits extremely outstanding durability under high potential, and the attenuations of its maximum power density and cell voltage at $600 \mathrm{~mA} \mathrm{~cm}^{-2}$ are only $4.8 \%$ and $3.6 \%$, respectively, which are far below those of the control prepared with commercial Pt/C. These results demonstrate that carbon materials with a graphite structure exhibit actual application potential in the preparation of octahedral catalysts. These carbon-supported octahedral catalysts are expected to be applied in PEMFC cathodes after the materials and preparation process are further improved.
\end{abstract}

Received 11th March 2018

Accepted 7th May 2018

DOI: 10.1039/c8ra02158a

rsc.li/rsc-advances
(111) facets have extremely high ORR activity, which is about 10 times that of the Pt (111) facets and approximately 90 times that of the commercial Pt/C catalyst. ${ }^{15,16}$ Its outstanding ORR activity is mainly attributed to the unique atomic and electronic structure of PtNi (111) facets. On the one hand, the Pt-Pt distance is reduced with the doping of $3 \mathrm{~d}$ transition metal $\mathrm{Ni}$, which is conducive to the adsorption of oxygen molecules on facets. On the other hand, the d-band structure of Pt on PtNi (111) facets is changed to improve selective adsorption for oxygen molecules because the appropriate d-band center position can promote the adsorption of oxygen molecules and decrease the adsorption of other oxygen species, which will reduce the coverage of impurities on facets and increase the exposure of active sites. ${ }^{17,18}$ Therefore, research on Pt-based octahedral catalysts with highly active (111) facets as the surface has been paid more attention, and various Pt-based octahedral catalysts have successfully emerged, some of which also show outstanding ORR performance compared with commercial Pt/C. ${ }^{19-23}$ However, this research was confined to the half cell performance of Pt-based octahedral catalysts, and there are few reports on their actual application in single cells.

Among the factors that affect the durability of catalysts, the corrosion of the carbon supports can not be ignored. Under vehicle operating conditions, the high potential resulting from the hydrogen/air interface formed during transient conditions, for example startup/shutdown, will easily cause carbon corrosion in cathodes. ${ }^{24}$ This carbon corrosion can result in decreases in the number and volume of the supports and the agglomeration of the nanocrystals, and the catalytic activity is
School of Automotive Studies \& Clean Energy Automotive Engineering Center, Tongji University, 4800 Caoan Road, Shanghai 201804, China. E-mail: zhangcunman@ tongji.edu.cn; libing210@tongji.edu.cn

$\dagger$ Electronic supplementary information (ESI) available. See DOI: $10.1039 / \mathrm{c} 8 \mathrm{ra02158a}$ 
then reduced. Moreover, oxygen containing functional groups appearing on the surface of the supports due to carbon oxidation will reduce the conductivity of the catalysts, which will cause the catalyst particles to easily sinter. ${ }^{25-28}$ These oxygen containing functional groups will also increase the hydrophilicity of the supports and affect gas permeability ${ }^{29}$ and drainage performance. In addition, carbon corrosion also reduces the thickness of catalyst layers and increases contact resistance, and thus affects the performance of fuel cells. ${ }^{30}$ To solve the problem of carbon corrosion, there is a more direct and effective way to improve support materials besides optimizing the system control strategy. Research demonstrates that the oxidation of carbon supports usually begins with defect sites on the carbon surface, while the graphite structure is helpful in avoiding defects and exhibits better thermal stability and electrochemical stability. ${ }^{31}$ Thus, carbon materials with a graphite structure can play an important role in enhancing the corrosion resistance of carbon supports. ${ }^{28,32,33}$ Vulcan XC-72 carbon black is the most commonly used support material, but its chemical and electrochemical stability need to be improved. ${ }^{31}$ Carbon nanotubes (CNTs) can be regarded as seamless and hollow tubes made of graphene sheets, and their graphite structure can effectively prevent support corrosion.

In order to make up for the deficiency of research on the durability and single cell performance of Pt-based octahedral catalysts, in this work, an octahedral PtNi catalyst was prepared with CNTs as a support using a facile surfactant-assisted solvothermal method, and the high potential durability of the membrane electrode assembly (MEA) fabricated using this catalyst in a cathode was also investigated. The electrochemical test results show that its ORR performance is better than that of the commercial Pt/C catalyst. Its mass activity and specific activity reach 5.5 and 8.5 times those of commercial $\mathrm{Pt} / \mathrm{C}$, respectively, and the attenuation of its electrochemical performance after a half cell durability test is also lower. After the high potential durability test, the MEA prepared with octahedral PtNi/CNTs exhibits an extremely high performance retention rate, and the attenuations of its cell voltage under $600 \mathrm{~mA} \mathrm{~cm}^{-2}$ and maximum power density are only $4.8 \%$ and $3.6 \%$, respectively. These results indicate that the Pt-based octahedral catalysts supported on carbon supports with a graphite structure have enhanced ORR activity and high support corrosion resistance, and they are expected to be applied in a PEMFC cathode after further optimization.

\section{Experimental section}

\subsection{Synthesis of the octahedral PtNi/CNT catalyst}

A one-step solvothermal method was selected to prepare the octahedral PtNi/CNT catalyst. Platinum acetylacetonate $\left(\mathrm{Pt}(\mathrm{acac})_{2}, 4 \mathrm{mM}\right)$ and nickel acetylacetonate $\left(\mathrm{Ni}(\mathrm{acac})_{2}, 10 \mathrm{mM}\right)$ as precursors, cetyltrimethylammonium bromide (CTAB, $4 \mathrm{mM}$ ) as a structure directing agent and CNTs $(81.62 \mathrm{mg})$ were dissolved into dimethylformamide (DMF, $70 \mathrm{~mL}$ ), a reducing agent and solvent, to form a uniform mixture. This was then placed into a $100 \mathrm{~mL}$ Teflon-lined stainless-steel autoclave. After sealing, the autoclave was heated at $160{ }^{\circ} \mathrm{C}$ for $12 \mathrm{~h}$, and was then cooled to room temperature. The products were filtrated and washed with ethanol and ultrapure water (18.2 M $\Omega$ ), then dried at $80{ }^{\circ} \mathrm{C}$ for $12 \mathrm{~h}$ and collected.

\subsection{Physical characterization}

Transmission electron microscopy (TEM) was carried out at 200 $\mathrm{kV}$ using a JEM 2010 EX microscope and TEM images were used to observe the morphology and dispersion of the catalyst. Scanning electron microscopy (SEM) was conducted using a FEI Sirion 200 to observe the structure and size of the CNTs. X-ray diffraction (XRD) was conducted using $\mathrm{CuK} \alpha$ radiation at a $2 \theta$ range from $20^{\circ}$ to $90^{\circ}$ at $0.05^{\circ} \mathrm{s}^{-1}$ on a Philips PW 3040/60 powder diffractometer, and XRD data were processed using Jade 6 software. The crystal sizes and lattice parameters of the nanocrystals were calculated according to the Scherrer equation and Bragg's law. Inductively coupled plasma mass spectrometry (ICP-MS) was employed to obtain the bulk composition of the catalyst.

\subsection{Electrochemical evaluation}

The catalyst was dispersed into a Nafion/methanol solution (mass ratio of $1: 30$ ) to obtain ink with a catalyst concentration of $2.0 \mathrm{mg} \mathrm{mL}{ }^{-1}$, and then $10 \mu \mathrm{L}$ ink was coated onto a glassy carbon (GC) electrode $\left(0.247 \mathrm{~cm}^{2}\right)$ as the working electrode, resulting in a Pt loading of $28 \mu \mathrm{g} \mathrm{cm}^{-2}$. A rotating disk electrode (RDE) technique and a three electrode system containing the above GC electrode, a platinum wire as the counter electrode and a reversible hydrogen electrode (RHE) as the reference electrode were employed to evaluate the ORR performance of the catalysts. The commercial $40 \mathrm{wt} \% \mathrm{Pt} / \mathrm{C}$ catalyst (Pt/C (JM), Johnson Matthey HiSpec 4000) was employed as the control. Cyclic voltammetry (CV) was carried out by sweeping a potential range from 0.05 to $1.15 \mathrm{~V} v s$. RHE at a scan rate of $50 \mathrm{mV} \mathrm{s}^{-1}$ in $\mathrm{N}_{2}$-saturated $0.1 \mathrm{M} \mathrm{HClO}_{4}$ solution. The electrochemically active surface area (ECSA) was calculated based on the area of the absorption and desorption peaks of hydrogen. Linear sweep voltammetry (LSV) was conducted under the same potential range at a scan rate of $5 \mathrm{mV} \mathrm{s}^{-1}$ at $1600 \mathrm{rpm}$ in $\mathrm{O}_{2}$-saturated $0.1 \mathrm{M} \mathrm{HClO}_{4}$ solution. Mass and specific activities were measured at $0.9 \mathrm{~V} v s$. RHE. Accelerated durability testing (ADT) was performed between 0.6 and $1.1 \mathrm{~V} v s$. RHE at $100 \mathrm{mV} \mathrm{s}^{-1}$ for 2000 cycles, and changes in the ECSA and mass activity before and after testing were used to evaluate the durability of the catalysts.

\subsection{Fabrication, characterization and high potential durability testing of the MEA}

The catalyst slurry was prepared by mixing catalyst, 5 wt $\%$ Nafion ${ }^{\circledR}$ solution (the mass ratio of the catalyst and Nafion was $3: 1$ ), ultrapure water and isopropanol under ultrasonication and stirring for $1 \mathrm{~h}$, and the mixture was then sprayed onto a membrane (GORE®, $50 \times 50 \mathrm{~mm}$ ) and dried. The MEA was obtained by fixing a pair of gas diffusion layers (GDLs) (SGL $28 \mathrm{BC}$ ) onto the as-prepared membrane. In order to evaluate the single cell performance of the as-prepared octahedral PtNi/CNT catalyst, a MEA was fabricated using the octahedral PtNi/CNT catalyst in the cathode and $40 \mathrm{wt} \% \mathrm{Pt} / \mathrm{C}(\mathrm{JM})$ in the anode with Pt loadings of $0.4 \mathrm{mg}_{\mathrm{Pt}} \mathrm{cm}^{-2}$ and $0.2 \mathrm{mg}_{\mathrm{Pt}} \mathrm{cm}^{-2}$ for the cathode 
and anode, respectively. For comparison, a control was also fabricated using Pt/C (JM) for both electrodes with the same Pt loadings as the above MEA. The same single cell tests were performed for both MEAs as follows. The polarization curves were obtained under the operating conditions of a cell temperature of $80{ }^{\circ} \mathrm{C}$, relative humidity $(\mathrm{RH})$ of $80 \%$, inlet gas pressure of 120 $\mathrm{kPa}$ and $\mathrm{H}_{2}$ /air stoichiometric ratio of 1.7/3.0 on a Greenlight fuel cell testing system. Electrochemical impedance spectroscopy (EIS) was conducted at $80{ }^{\circ} \mathrm{C}$ and a $\mathrm{RH}$ of $80 \%$ under $0.8 \mathrm{~V} v s$. RHE at a frequency range from $1000 \mathrm{~Hz}$ to $0.1 \mathrm{~Hz}$. In situ CV curves were measured at $80{ }^{\circ} \mathrm{C}$ and a $\mathrm{RH}$ of $100 \%$ between 0.05 and $1.15 \mathrm{~V} v$ s. RHE at $20 \mathrm{mV} \mathrm{s}^{-1}$ with the cathode and anode supplied with $\mathrm{N}_{2}$ and $\mathrm{H}_{2}$ at $200 \mathrm{~mL} \min ^{-1}$, respectively. In the high potential durability test, under a cell temperature of $80{ }^{\circ} \mathrm{C}$ and a RH of $100 \%$, MEAs were kept under a constant voltage of $1.5 \mathrm{~V} v$ s. RHE for $1 \mathrm{~h}$ with $\mathrm{N}_{2}$ and $\mathrm{H}_{2}$ at $200 \mathrm{~mL} \mathrm{~min}^{-1}$ supplied to the cathode and anode, respectively. After the high potential durability test, polarization curves, EIS and in situ CV curves were also obtained under the above single cell operating conditions.

\section{Results and discussion}

\subsection{Morphology and composition of the octahedral PtNi/ CNT catalyst}

The TEM images shown in Fig. 1a and b demonstrate that the octahedral nanocrystals were successfully prepared, and the as- prepared nanocrystals are dispersed well on the CNTs with diameters of around $15-20 \mathrm{~nm}$ as shown in Fig. 1d. The histogram of the particle size distribution of the octahedral PtNi/CNT catalyst inset in Fig. 1a shows that the average particle size is about $12.8 \mathrm{~nm}$. The high resolution transmission electron microscopy (HRTEM) image in Fig. 1c shows a well-defined octahedral nanocrystal with (111) facets at the surface, and its (111) facet spacing is $2.15 \AA$, which is smaller than that of pure Pt due to the doping of Ni which has a smaller atomic radius. We suggest that the octahedral morphology of the nanocrystals is attributed to the specific adsorption of CTAB on PtNi (111) facets which decreases its surface energy and slows facet growth, and thus it is beneficial to the exposure of (111) facets.

XRD patterns of the octahedral PtNi/CNT catalyst and Pt/C (JM) are exhibited in Fig. 2. In the XRD pattern of the octahedral PtNi/CNT catalyst, the peak located at $25.7^{\circ}$ is the graphite (002) peak of CNTs, and the diffraction peaks located at $42.0^{\circ}$, $48.7^{\circ}, 71.7^{\circ}$, and $86.4^{\circ}$ can be assigned to the (111), (200), (220) and (311) facets, respectively, indicating that the octahedral PtNi nanocrystals have a face centered cubic (fcc) structure. In addition, no diffraction peaks of pure Ni or oxide species can be observed, and the diffraction peaks of the octahedral nanocrystals shift to higher $2 \theta$ angles than the corresponding peaks of pure Pt, and appear between those of pure Pt and pure $\mathrm{Ni}$, demonstrating that a PtNi alloy state is formed. Due to its smaller full width at half-maximum (FWHM) and higher $2 \theta$

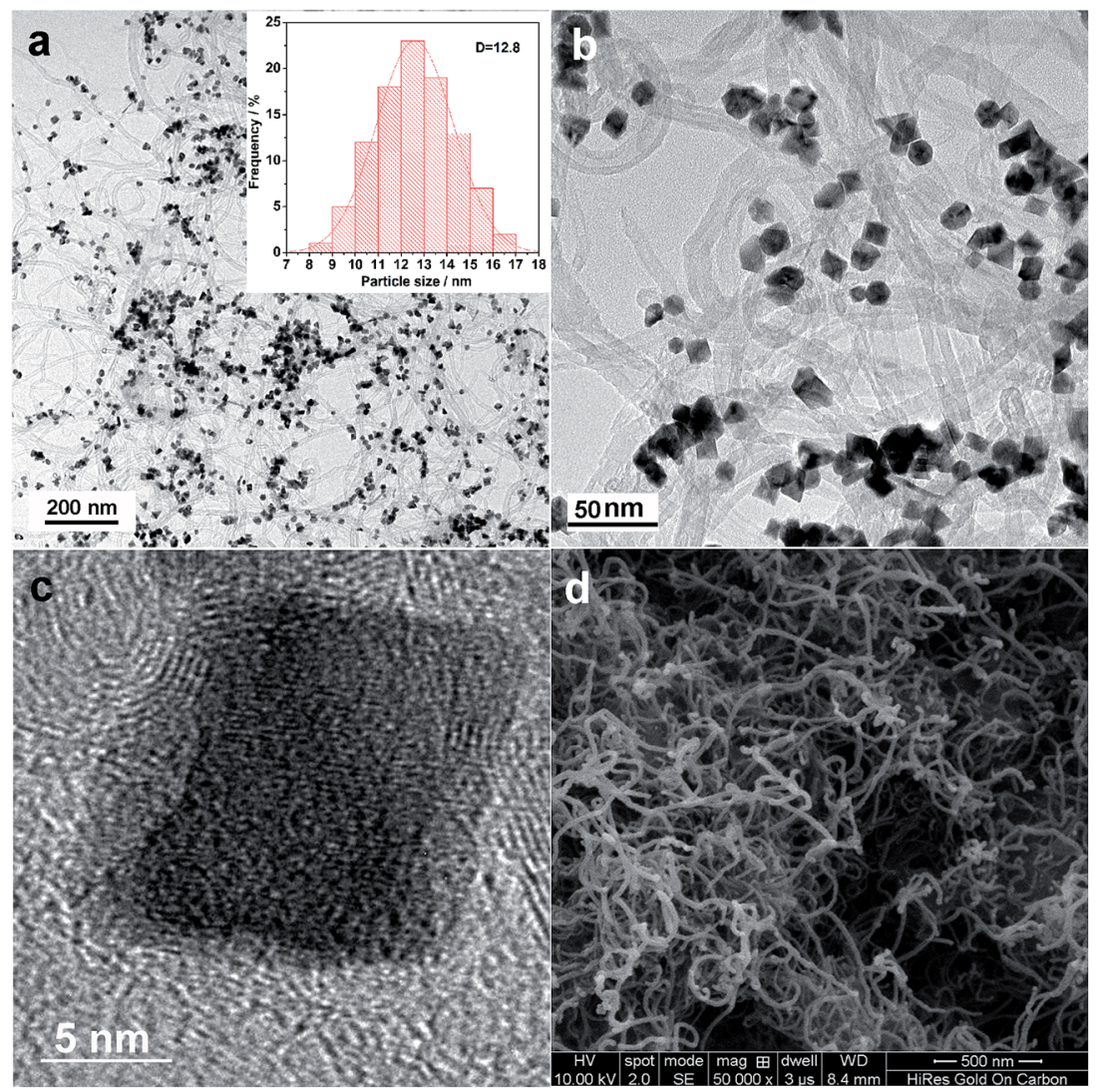

Fig. 1 (a and b) TEM images of the octahedral PtNi/CNT catalyst. (c) HRTEM image of an individual PtNi octahedral nanocrystal. (d) SEM image of CNTs. 


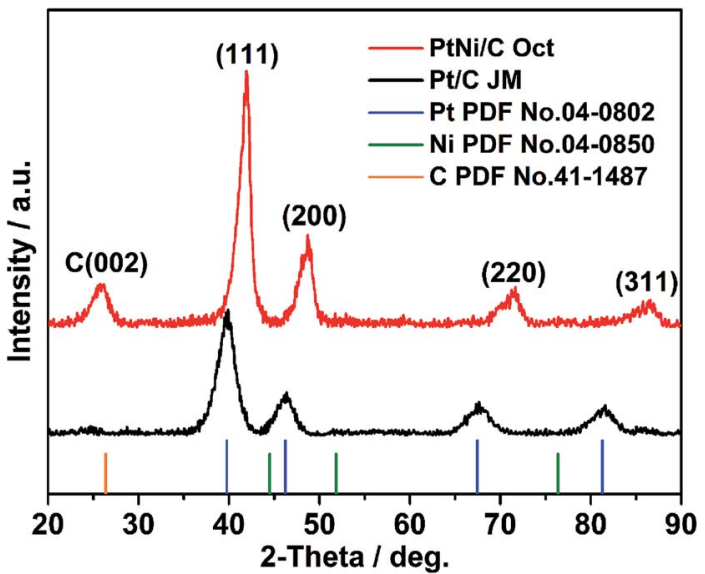

Fig. 2 XRD patterns of the octahedral PtNi/CNT catalyst and Pt/C (JM).

angle, the octahedral nanocrystal shows a greater crystal size and smaller lattice parameter as listed in Table $\mathrm{S} 1, \dagger$ which conforms with the above TEM images.

The composition of the octahedral PtNi/CNT catalyst measured using ICP is $30.17 \mathrm{wt} \% \mathrm{Pt}$ and $9.31 \mathrm{wt} \% \mathrm{Ni}$, respectively, that is, the atom ratio of Pt and $\mathrm{Ni}$ is nearly $1: 1$. In this paper, calculations of element content are carried out according to this ratio.

\subsection{ORR activity and durability of the octahedral PtNi/CNT catalyst}

Fig. 3 shows the CV and LSV curves of the octahedral PtNi/CNT catalyst and $\mathrm{Pt} / \mathrm{C}(\mathrm{JM})$, and their ORR activity parameters at $0.9 \mathrm{~V}$ vs. RHE are shown in Table 1. In Fig. 3a, hydrogen adsorption/ desorption peaks appear in the region from 0.05 to $0.35 \mathrm{~V}$, and oxygen adsorption/desorption peaks appear in the region from 0.6 to $1.15 \mathrm{~V}$. The peak areas of $\mathrm{Pt} / \mathrm{C}$ (JM) are obviously larger than those of the octahedral PtNi/CNT catalyst, which may be caused by a great difference in their crystal sizes, in accordance with TEM and XRD results. The LSV curve of the octahedral PtNi/CNT catalyst in Fig. 3b exhibits a higher half-wave potential, signifying enhanced ORR activity. Its mass activity and specific activity at $0.9 \mathrm{~V} v$ s. RHE are approximately 5.5 and 8.5 times those of Pt/C (JM), respectively. Reducing the theoretical Pt usage of $82.1 \%$ in a cathode can be achieved by obtaining higher mass activity, which is conducive to reducing cost. We suggest its enhanced ORR activity is mainly due to PtNi alloying and its well-defined octahedral morphology. Through forming an alloy with $\mathrm{Ni}$, the Pt-Pt atomic distance can be reduced and the d-band structure is also changed, which makes it more suitable for oxygen selective adsorption. ${ }^{\mathbf{1 6 , 3 4 - 4 0}}$ The surface of the as-prepared octahedral nanocrystal is composed of PtNi (111) facets with extremely high ORR activity, and more active sites can be supplied. ${ }^{15,16}$ Therefore, enhanced mass activity can be realized though the octahedral PtNi/CNT catalyst exhibits a lower ECSA.

In order to investigate the durability of the octahedral PtNi/ CNT catalyst in an electrochemical environment, ADT was
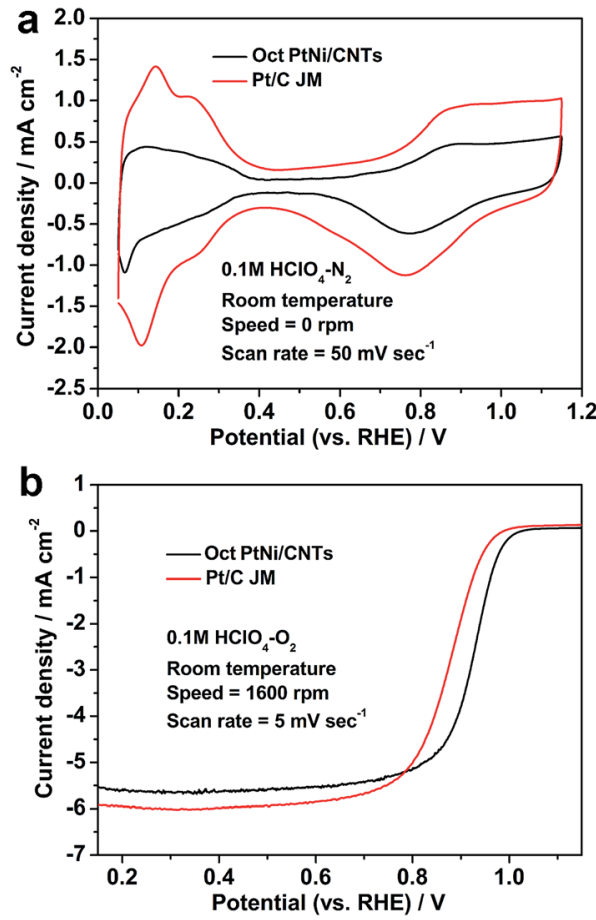

Fig. 3 (a) CV and (b) LSV curves of the octahedral PtNi/CNT catalyst and $\mathrm{Pt} / \mathrm{C}(\mathrm{JM})$.

Table 1 The ECSA and ORR activity at $0.9 \mathrm{~V}$ vs. RHE of the octahedral $\mathrm{PtNi} / \mathrm{CNT}$ catalyst and Pt/C (JM)

\begin{tabular}{llll}
\hline Catalyst & $\begin{array}{l}\text { ECSA } \\
\left(\mathrm{m}^{2} \mathrm{~g}_{\mathrm{Pt}}{ }^{-1}\right)\end{array}$ & $\begin{array}{l}\text { Mass activity } \\
\left(\mathrm{mA} \mathrm{mg}_{\mathrm{Pt}}{ }^{-1}\right)\end{array}$ & $\begin{array}{l}\text { Specific activity } \\
\left(\mu \mathrm{A} \mathrm{cm}{ }_{\mathrm{Pt}}{ }^{-2}\right)\end{array}$ \\
\hline Oct PtNi/CNTs & 34.8 & 479.0 & 1376.4 \\
Pt/C $(\mathrm{JM})$ & 53.2 & 86.4 & 162.4 \\
\hline
\end{tabular}

performed, and the CV and LSV curves of the octahedral PtNi/ CNT catalyst and Pt/C (JM), before and after ADT, are presented in Fig. 4 and Fig. S1, $\dagger$ and bar charts in Fig. S2 $\uparrow$ show the changes in their ECSAs and mass activities at $0.9 \mathrm{~V} v s$. RHE. After the durability test of 2000 cycles, the ECSA, mass activity and specific activity of $\mathrm{Pt} / \mathrm{C}$ (JM) are reduced by $38.9 \%, 64.6 \%$ and $42.0 \%$, respectively, whereas the attenuation rates of these parameters for the octahedral PtNi/CNT catalyst are only $27.9 \%$, $33.6 \%$ and $8.0 \%$, respectively. In particular, its remaining mass activity is 10.4 times higher than the corresponding remaining mass activity of $\mathrm{Pt} / \mathrm{C}(\mathrm{JM})$, and even reaches 3.7 times the initial one of $\mathrm{Pt} / \mathrm{C}$ (JM). The ADT results demonstrate that the octahedral PtNi/CNT catalyst shows improved half cell durability compared with Pt/C (JM). Fig. S3† shows TEM images of Pt/C (JM) before and after ADT. The growth and agglomeration of the nanocrystals can be obviously observed. We infer that the better retention of ORR performance of the octahedral PtNi/ CNT catalyst may be ascribed to the stability of its size and morphology due to the larger crystal size of the octahedral nanocrystals and better corrosion resistance of the CNTs. However, the durability of the octahedral PtNi/CNT catalyst still 

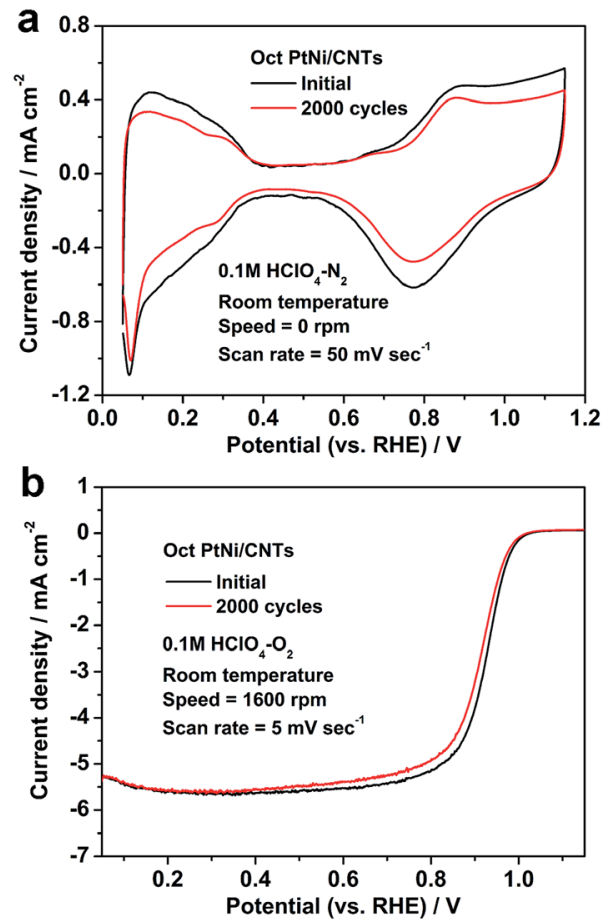

Fig. 4 (a) CV and (b) LSV curves of the octahedral PtNi/CNT catalyst before and after ADT.

needs to be further improved. The TEM image in Fig. S4† exhibits the nanocrystal after ADT. Its crystal size is not significantly increased, but its morphology becomes smooth. Therefore, we suggest that the decrease in its activity is mainly due to changes in morphology and loss of PtNi (111) facets caused by $\mathrm{Ni}$ atoms dissolving and leaching out of the alloy under acidic conditions, ${ }^{21}$ and thus its durability could be improved by surface modification or doping with stable metal elements, such as $\mathrm{Au}$, Mo and so on.

\subsection{Single cell performance and high potential durability of the octahedral PtNi/CNT catalyst}

To evaluate the single cell performance of the octahedral PtNi/ CNT catalyst, the MEA fabricated using the as-prepared octahedral catalyst in the cathode was tested under the operating conditions described in Section 2.4, and the results are shown in Fig. 5. Its maximum power density and cell voltage at a current density of $600 \mathrm{~mA} \mathrm{~cm}{ }^{-2}$ are $432.6 \mathrm{~mW} \mathrm{~cm}^{-2}$ and $0.643 \mathrm{~V}$, respectively. According to Fig. S5, $\dagger$ its maximum power density, calculated using the total Pt loading in both electrodes, is $0.721 \mathrm{~kW} \mathrm{~g}_{\mathrm{Pt}}{ }^{-1}$, and thus the Pt loading calculated based on unit power is $1.39 \mathrm{~g}_{\mathrm{Pt}} \mathrm{kW}^{-1}$. The ECSA in a single cell calculated through the in situ $\mathrm{CV}$ curve of the octahedral PtNi/CNT catalyst shown in Fig. 6 is $25.7 \mathrm{~m}^{2} \mathrm{~g}_{\mathrm{Pt}}{ }^{-1}$, which is reduced by almost $26.1 \%$ compared with the result from the RDE test. The cathode charge transfer resistance obtained from the diameter of the semicircle between high frequency and low frequency ${ }^{\mathbf{4 1}}$ in the EIS results shown in Fig. 7 is also high. Although the octahedral PtNi/CNT catalyst shows better ORR activity, its single cell

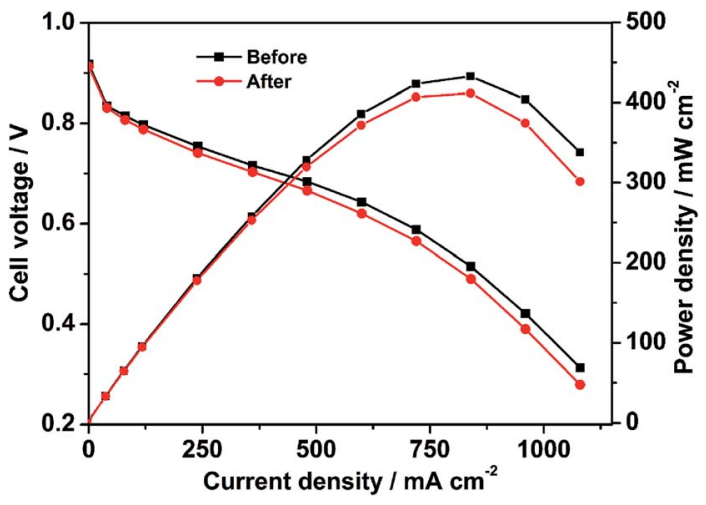

Fig. 5 The polarization curves of the MEA, fabricated using the octahedral PtNi/CNT catalyst in the cathode, measured by the area of the MEA before and after a high potential durability test.

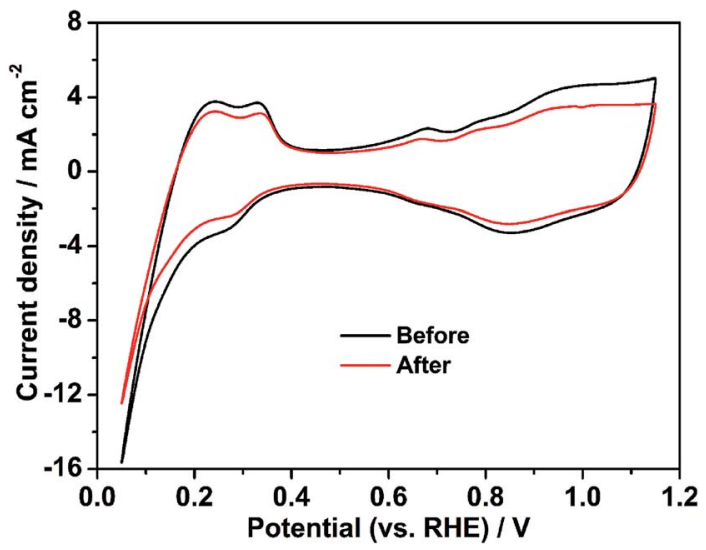

Fig. 6 The in situ CV curves of the MEA fabricated using the octahedral PtNi/CNT catalyst in the cathode before and after a high potential durability test.

performance is unsatisfactory compared with the MEA fabricated using Pt/C (JM). The performance curves are presented in Fig. S6. $\dagger$ As a control, the ECSA of a single cell is $50.9 \mathrm{~m}^{2} \mathrm{~g}_{\mathrm{Pt}}{ }^{-1}$, which is about $5 \%$ less than that obtained in the RDE test,

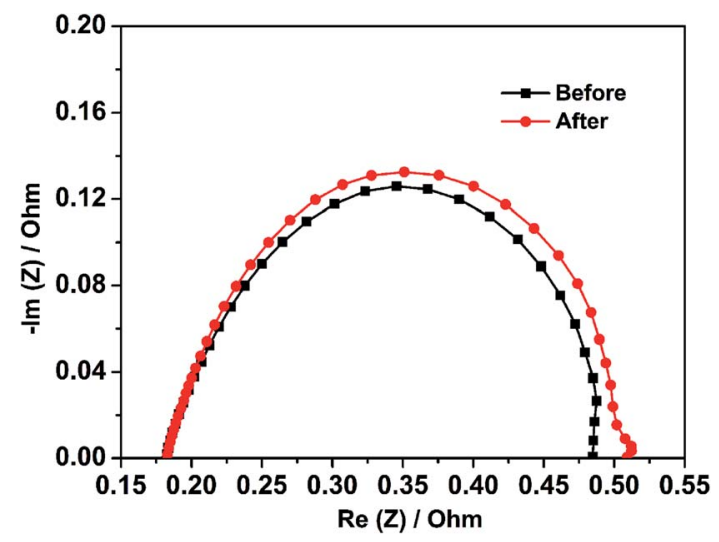

Fig. 7 The EIS results of the MEA fabricated using the octahedral PtNi/ CNT catalyst in the cathode before and after a high potential durability test. 
revealing very high Pt utilization in the MEA. From the above results, a greatly decreased ECSA indicates that the utilization rate of the octahedral PtNi/CNT catalyst in the single cell is lower. In half cell tests, sufficient contact between the catalyst and the electrolyte can be realized due to the extremely thin catalyst layer on the working electrode, so the catalyst utilization rate is high. However, in the single cell, the electrode reactions occur on the active sites named the "three phase boundary" (TPB), where electrons, protons and gas can simultaneously come into contact with active components. In order to ensure that protons can be successfully transferred to reaction sites, ionomers that fully come into contact with the active components play an important role. In the dispersing process of catalyst slurry, CNTs easily intertwine, which will hinder the contact between ionomers and active components, and reduce the effective utilization of the catalyst. Therefore, the asfabricated MEA shows unsatisfactory power generation performance. This may need to be solved by optimizing the support and improving the MEA preparation process.

As presented in Fig. S6, $\uparrow$ the control fabricated using Pt/C (JM) exhibits an extremely great attenuation after the high potential durability test, and its maximum power density, cell voltage at $600 \mathrm{~mA} \mathrm{~cm}^{-2}$ and ECSA are reduced by $33.6 \%, 16.7 \%$ and $80.9 \%$, respectively. Because Pt is passivated at about $1.2 \mathrm{~V}$, the dissolution of $\mathrm{Pt}$ can be ignored at the high potential of $1.5 \mathrm{~V}$. In addition, oxidized Pt will be reduced in the CV test, which is not enough to cause a large drop in the ECSA. Therefore, we conclude that the shedding and loss of Pt resulting from the corrosion of the carbon support is the main reason for the decline of single cell performance according to a serious loss in the ECSA. ${ }^{4,43}$ The red and black lines shown in Fig. 5-7 exhibit comparisons of the polarization curves, in situ CV curves and EIS results of a MEA fabricated using the octahedral PtNi/ CNT catalyst in the cathode before and after a high potential durability test, and their performance parameters are listed in Table 2. Under the same testing conditions as the control, the maximum power density, cell voltage at $600 \mathrm{~mA} \mathrm{~cm}^{-2}$ and ECSA in a single cell are decreased by only $4.8 \%, 3.6 \%$ and $12.8 \%$, respectively, and the cathode charge transfer resistance is also only slightly increased. These results demonstrate that the asprepared octahedral PtNi/CNT catalyst has extremely outstanding high potential durability in a single cell. We think that the excellent corrosion resistance of CNTs with a graphite structure plays a critical role in inhibiting the oxidation of the carbon support under high potential and maintaining the original structure and properties of the catalyst layer. ${ }^{31-33}$ Accordingly, though the single cell performance still needs to be

Table 2 Comparison of the performance of the MEA fabricated using the octahedral PtNi/CNT catalyst in the cathode before and after a high potential durability test

\begin{tabular}{llll}
\hline Catalyst & $\begin{array}{l}\text { Maximum power } \\
\text { density }\left(\mathrm{mW} \mathrm{cm}{ }^{-2}\right)\end{array}$ & $\begin{array}{l}\text { Cell voltage@ } \\
600 \mathrm{~mA} \mathrm{~cm}^{-2}(\mathrm{v})\end{array}$ & $\begin{array}{l}\text { ECSA } \\
\left(\mathrm{m}^{2} \mathrm{~g}_{\mathrm{Pt}}{ }^{-1}\right)\end{array}$ \\
\hline Before & 432.6 & 0.643 & 25.7 \\
After & 411.6 & 0.620 & 22.4
\end{tabular}

improved as a result of the selected support and preparation technique, we believe that this supported octahedral PtNi catalyst has a certain application value under high potential, if the graphitization of well-dispersed carbon supports and making full use of the active components can be achieved.

\section{Conclusion}

In summary, the octahedral PtNi/CNT catalyst was successfully synthesized using a facile surfactant-assisted solvothermal process. In a RDE test, it exhibited better ORR activity and durability. Its mass activity and specific activity at $0.9 \mathrm{~V} v s$. RHE are 5.5 and 8.5 times those of the commercial $\mathrm{Pt} / \mathrm{C}$, respectively, and the retention rate of its ORR performance is also higher after ADT. In addition, the MEA fabricated using the octahedral $\mathrm{PtNi} / \mathrm{CNT}$ catalyst in the cathode demonstrates extremely high performance retention rates after a high potential durability test, and the attenuations of both the maximum power density and cell voltage at $600 \mathrm{~mA} \mathrm{~cm} \mathrm{~cm}^{-2}$ are less than $5 \%$. Although there is potential to increase the single cell performance of the octahedral PtNi/CNT catalyst, our research still proves that carbon materials with a graphite structure as supports have application potential in preparing octahedral catalysts. After further improving the materials and preparation process, we insist that carbon-supported Pt-based octahedral catalysts with prominent high potential durability should be expected to be applied in PEMFC cathodes.

\section{Conflicts of interest}

There are no conflicts to declare.

\section{Acknowledgements}

The authors thank the National Natural Science Foundation (No. 21676204).

\section{Notes and references}

1 M. Ball and M. Wietschel, Int. J. Hydrogen Energy, 2009, 34, 615-627.

2 B. Hum and X. G. Li, Two-dimensional analysis of PEM fuel cells, J. Appl. Electrochem., 2004, 34, 205-215.

3 J. Larminie and A. Dicks, Fuel Cell Systems Explained, 2nd edn, UK, 2003.

4 J. K. Norskv, J. Rossmeisl and A. Logadottir, J. Phys. Chem. B, 2004, 108, 17886-17892.

5 H. Y. Zhang, R. Lin, C. H. Cao, J. Zhao and J. X. Ma, Electrochim. Acta, 2011, 56, 7622-7627.

6 Z. M. Peng and H. Yang, Nano Today, 2009, 4, 143-164.

7 R. F. Wang, S. J. Liao, H. Y. Liu and H. Meng, J. Power Sources, 2007, 171, 471-476.

8 N. Toshima, R. Ito, T. Matsushita and Y. Shiraishi, Catal. Today, 2007, 122, 239-244.

9 Y. J. Kang, J. Snyder, M. F. Chi, D. G. Li, K. L. More, N. M. Markovic and V. R. Stamenkovic, Nano Lett., 2014, 14, 6361-6367. 
10 X. L. Sun, D. G. Li, Y. Ding, W. L. Zhu, S. J. Guo, Z. L. Wang and S. H. Sun, J. Am. Chem. Soc., 2014, 136, 5745-5749.

11 W. Shimizu, K. Okada, Y. Fujita, S. S. Zhao and Y. Murakami, J. Power Sources, 2012, 205, 24-31.

12 S. J. Guo, D. G. Li, H. Y. Zhu, S. Zhang, N. M. Markovic, V. R. Stamenkovic and S. H. Sun, Angew. Chem., Int. Ed., 2013, 52, 3465-3468.

13 M. Górzny, A. S. Walton and S. D. Evans, Adv. Funct. Mater., 2010, 20, 1295-1300.

14 L. Gancs, T. Kobayashi, M. K. Debe, R. Atanasoski and A. Wieckowski, Chem. Mater., 2008, 20, 2444-2454.

15 V. R. Stamenkovic, B. Fowler and B. S. Mun, Science, 2007, 315, 493-497.

16 V. R. Stamenkovic, B. S. Mun, M. Arenz, K. J. J. Mayrhofer, C. A. Lucas, G. F. Wang, P. N. Ross and N. M. Marković, Nat. Mater., 2007, 6, 241.

17 N. Jung, D. Y. Chung, J. Ryua, S. J. Yoo and Y. E. Sun, Nano Today, 2014, 9, 433-456.

18 J. Wang, B. Li, T. Yersak, D. J. Yang, Q. F. Xiao, J. L. Zhang and C. M. Zhang, J. Mater. Chem. A, 2016, 4, 11559-11581.

19 S. Ryogo, O. Kaoru, F. Terumi and I. Masao, J. Power Sources, 2014, 269, 117-123.

20 C. H. Cui, L. Gan, H. H. Li, S. H. Yu, M. Heggen and P. Strasser, Nano Lett., 2012, 12, 5885.

21 C. H. Cui, L. Gan, M. Heggen, S. Rudi and P. Strasser, Nat. Mater., 2013, 12, 765-771.

22 X. Q. Huang, Z. P. Zhao, Y. Chen, E. B. Zhu, M. F. Li, X. F. Duan and Y. Huang, Energy Environ. Sci., 2014, 7, 2957-2962.

23 X. Q. Huang, Z. P. Zhao, L. Cao, Y. Chen, E. B. Zhu, Z. Y. Lin, M. F. Li, A. M. Yan, A. Zettl, M. Y. Wang, X. F. Duan, T. Mueller and Y. Huang, Science, 2015, 348, 1230-1234.

24 S. Maass, F. Finsterwalder and G. Frank, J. Power Sources, 2008, 176, 444-451.

25 Y. Shao, G. Yin and Y. Gao, J. Power Sources, 2007, 171, 558-566.

26 K. H. Kangasniemi, D. A. Condit and T. D. Jarvi, J. Electrochem. Soc., 2004, 151, E125-E132.
27 M. Cai, M. S. Ruthkosky and B. Merzougui, J. Power Sources, 2006, 160, 977-986.

28 F. Coloma, A. Sepulvedaescribano and F. Rodriguezreinoso, J. Catal., 1995, 154, 299-305.

29 Z. Siroma, N. Fujiwara and T. Ioroi, J. Power Sources, 2004, 126, 41-45.

30 E. Guilminot, A. Corcella and F. Charlot, J. Electrochem. Soc., 2007, 154, B96-B105.

31 D. Stevens, M. Hicks and G. Haugen, J. Electrochem. Soc., 2005, 152, A2309-A2315.

32 B. Eastwood, P. Christensen and R. Armstrong, J. Solid State Electrochem., 1999, 3, 179-186.

33 Y. Shao, G. Yin and J. Zhang, Electrochim. Acta, 2006, 51, 5853-5857.

34 I. E. L. Stephens, A. S. Bondarenko, U. Grønbjerg, J. Rossmeisl and I. Chorkendorff, Energy Environ. Sci., 2012, 5, 6744-6762.

35 C. Wang, M. Chi, G. Wang, D. Vliet, D. Li, K. More, H. H. Wang, J. A. Schlueter, N. M. Markovic and V. R. Stamenkovic, Adv. Funct. Mater., 2011, 21, 147.

36 Y. Bing, H. Liu, L. Zhang, D. Ghosh and J. Zhang, Chem. Soc. Rev., 2010, 39, 2184.

37 P. Liu and J. K. Nørskov, Phys. Chem. Chem. Phys., 2001, 3, 3814-3818.

38 J. R. Kitchin, J. K. Nørskov, M. A. Barteau and J. G. Chen, J. Chem. Phys., 2004, 120, 10240-10246.

39 N. M. Marković, H. A. Gasteiger, B. N. Grgur and P. N. Ross, J. Electroanal. Chem., 1999, 467, 157-163.

40 B. Hammer and J. K. Nørskov, Adv. Catal., 2000, 45, 71-129.

41 B. Li, R. Lin, D. J. Yang and J. X. Ma, Int. J. Hydrogen Energy, 2010, 35, 2814-2819.

42 T. A. Bekkedahl, L. J. Bregoli, R. D. Breault, E. A. Dykeman, J. P. Meyers, T. W. Patterson, T. Skiba, C. Vargas, D. Yang and J. S. Yi, US pat., 6913 845, 2005.

43 C. R. Reiser, L. Bregoli, T. W. Patterson, J. S. Yi, J. D. Yang, M. L. Perry and T. D. Jarvi, Electrochem. Solid-State Lett., 2005, 8, A273. 